\title{
SYNTHESIS OF NEW BORON COMPOUNDS WITH AMOXICILLIN AND SOME OF ITS METAL COMPLEXES WITH USE THEM IN ANTIBACTERIAL, ASSESSMENT OF HEPATOPROTICTIVE AND KIDNEYACTIVITY, ANTICANCER AND ANTIOXIDANT APPLICATIONS
}

\author{
GHANEM SH AL-JEBOURI*, ASMAA MOHAMMED NOORIKHALEEL
}

Department of Chemistry, College of Sciences, University of Baghdad, Baghdad, Iraq. Email: ghanemshaker93@gmail.com Received: 22 November 2018, Revised and Accepted: 29 December 2018

ABSTRACT

Objective: New ligand (\{7-[2-amino-2-(4-hydroxyphenyl)-acetamido-3,3-dimethyl-6-oxo-2-thia-5-aza bicyclo[3,2,0]heptane-4-carboxylic boric anhydride\}) with its $\mathrm{Co}$ (II), Ni (II) and Cu (II) complexes. And new mixed ligand copper complex was synthesized.

Methods: The ligand was synthesized by the reaction of boric acid with amoxicillin (1:1) and the mixed ligand complex has been synthesized by the reaction of the ligand, 4-aminoantipyrine and $\mathrm{Cu}(\mathrm{II})$ ion (1:1:1).

Results: All studied compounds were characterized by the spectral method: Fourier transform infrared, ultraviolet-visible, thermal analysis (TG and DTG), flame atomic absorption and nuclear magnetic resonance. Also CHNS, melting point, magnetic susceptibility and molar conductivity.

Conclusion: According to the obtained data, all complexes were non electrolyte and the geometry was octahedral for all complexes. All synthesized compounds were tested as antibacterial agents against Escherichia Coli, Pseudomonas auroginosa as Gram-negative bacteria (G-) and Staphylococcus aureus epidermis as Gram-positive bacteria (G+). The results showed that copper complexes were more active in (10-2M) than the other compounds. The medicinal applications (hepatoprotective and kidney in serum of mice, histopathological of liver and kidney, anticancer and antioxidant in human cell were studied of the synthesized compounds and gave a good results in all tested.

Keywords: Boron compounds, Boric acid, Amoxicillin, Anticancer, Antioxidant.

(c) 2019 The Authors. Published by Innovare Academic Sciences Pvt Ltd. This is an open access article under the CC BY license (http://creativecommons. org/licenses/by/4. 0/) DOI: http://dx.doi.org/10.22159/ajpcr.2019.v12i3.30912

\section{INTRODUCTION}

Boric acid and borates are exists in water, food and soil. They are used as least toxic pesticides to kill insects, mites, fungi, algae, fleas and wood decay fungi [1]. The mechanism of killing contains working to poison the stomach and absorbing the waxes which protect insects. Also boric acid used as antiseptic in talcum powder, mouth-washes, eyewashes and protective ointments. Another application includes reducing the flammability of cellulosic materials used in production of leather [2].

Amoxicillin trihydrate (2-Amino-2,3,3-dimethyl-7-oxo-4-thia-1-azabicyclo [3.2.0] heptane-2-carboxylic acid) [3]. The amoxicillin is a widely used in biological and pharmaceutical applications [4]. It is used as respiratory, veterinary medicine to treatment the gastrointestinal, antibiotic in human medicine as well as skin and urinary bacterial infections [5].

4-Aminoantipyrine (4-amino-2,3-dimethyl1-phenyl-3-pyrazolin-5one (4-AAP)) [6] is one of aromatic compounds which has a special properties and used as antipyretic, anti-inflammatory, analgesic, antimicrobial and anticancer [6].

In the present work we are synthesis a new derivative of amoxicillin with boric acid, also the metal complexes of this derivative (ligand) with Co (II), Ni (II) and Cu (II) ions were synthesized. We are synthesis a mixed ligand complex from the reaction of amoxicillin and 4-aminoantipyrine with $\mathrm{Cu}$ (II) ion. The medincinal applications and the biological activity were studied for all synthesized compounds.

\section{EXPERIMENTAL PART}

\section{Chemicals}

All chemicals were used as received without further purification (supplied by BDH, Spain, Aldrich, Merck, FlukaAG, BuchsSG, LOBA Chime, Hayman. Fluka-Garantie and fieser).

\section{METHODS}

Synthesis of 7-[2-amino-2-(4-hydroxyphenyl)-acetamido-3,3dimethyl-6-oxo-2-thia 5 -aza bicyclo $[3,2,0]$ heptane-4-carboxylic boric anhydride (L) (Fig. 1)

The mixture of amoxicillin trihydrate $(0.1 \mathrm{~g}, 0.238 \mathrm{mmol})$ in $10 \mathrm{~mL}$ $\mathrm{H} 2 \mathrm{O}$ and boric acid $(0.0147 \mathrm{~g}, 0.238 \mathrm{mmol})$ in $1 \mathrm{~mL} \mathrm{H} 2 \mathrm{O}$ was heated under reflux for $17 \mathrm{~h}$ with stirring. The resulting solution was heated to evaporate part of a solvent and then diethyl ether was added in presence of ice-bath and crushing to precipitate the yellow product, washed with hot water and dried in oven.

Synthesis of metal complexes with Co (II), Ni (II) and Cu (II) (C1-C3) The mixture of $\mathrm{L}(0.1 \mathrm{~g}, 0.244 \mathrm{mmol})$ in $5 \mathrm{~mL}$ methanol and metal salt (0.244 mmol, $0.058,0.057$ and $0.041 \mathrm{~g}$ ) of $\mathrm{CoCl}_{2} \cdot 6 \mathrm{H}_{2} \mathrm{O}, \mathrm{NiCl}_{2} \cdot 6 \mathrm{H}_{2} \mathrm{O}$ and $\mathrm{CuCl}_{2} \cdot 2 \mathrm{H}_{2} \mathrm{O}$ respectivly in $1 \mathrm{~mL}$ methanol was heated under reflux for (5) h with stirring. The part of solvent was evaporated and diethyl ether was added in presence of ice-bath and crushing to increase the quantity of product, washed with methanol and dried in oven.

\section{Synthesis of mixed ligand complex with $\mathrm{Cu}$ (II) ion (Mix.)}

The mixture of $\mathrm{L}(0.115 \mathrm{~g}, 0.281 \mathrm{mmol})$ in $3 \mathrm{~mL}$ methanol, 4-aminoantipyrine $(0.057 \mathrm{~g}, 0.281 \mathrm{mmole})$ in $1 \mathrm{~mL}$ methanol and $\mathrm{CuCl}_{2} \cdot 2 \mathrm{H}_{2} \mathrm{O}(0.048 \mathrm{~g}, 0.281 \mathrm{mmole})$ in $1 \mathrm{~mL}$ methanol was heated under reflux for $5 \mathrm{~h}$. Part of solvent was evaporated and diethyl ether was added in presence of ice-bath and crushing to increase the product. The black product washed several time with methanol and dried in oven.

\section{Antibactrial activity}

Antibactrial activity of the ligand and its metal complexes was studied against Pseudomonas auroginosa and Escherichia Coli as Gram-negative (G-) and S. aureus as Gram-positive (G+) by the agar well-diffusion 
method. The concentration of solutions were $10^{-2}$ and $10^{-3} \mathrm{M}$ in description dimethyl sulfoxide (DMSO) and incubated at $37^{\circ} \mathrm{C}$ for $24 \mathrm{~h}$.

\section{The hepatoprotective and kidney effects}

The hepatoprotective and kidney effects were evaluation in mice which treated with the ligand $(\mathrm{L})$, Copper complex $\left(\mathrm{C}_{3}\right)$ and mixed ligand complex (Mix). This test included liver function test glutamic oxaloacetic transaminase (GOT), glutamate pyruvate transaminase (GPT) and alkaline phosphatase (ALP) and kidney function (Urea, Creatinine, Albumin (Alb), Total serum protein (TSP) test and in serum.

\section{The hepatoprotective test}

The commercial kit of GOT, GPT and ALP were (Randox company) method $[7,8]$.

\section{The kidney function test}

The commercial kit of urea, creatinine, Alb and TSP were (Agappe company) method [9-11].

\section{Statistical analysis}

The values of the investigated parameters were given in terms of mean \pm standard error, by using the computer programmer SPSS version 13.0 [12].

\section{Histopathological study}

After blood collection, the mouse was dissected and to obtain the liver and kidney. The histopathological examination was adopted on the litreture [13].

\section{Anticancer and antioxidant activity}

The MTT cell viability assay was worked using 96-well plate for determination of cytotoxic effect. The cell lines were seeded at $1 \times 104$ cells/well. After $24 \mathrm{~h}$, cell were treated with studied compounds. The study of anticancer effectiveness was based on literature [14] and the absorbance was measured at $492 \mathrm{~nm}$.

Antioxidant activity of $\mathrm{x}$-substance was determined using stable DPPH radicals as well as the minor modification [15].

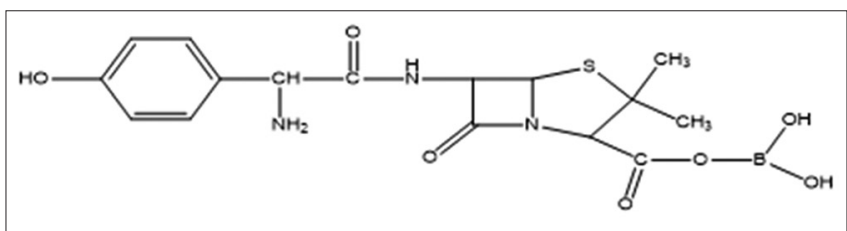

Fig. 1: 7-[2-Amino-2-(4-hydroxyphenyl)-acetamido-3,3-dimethyl6-oxo-2-thia 5 -aza bicyclo[3,2,0]heptane-4-carboxylic boric anhydride (L)

\section{RESULTS AND DISCUSSION}

Physical properties and elemental analysis

The physical properties, elemental and analytical data are illustrated in Table 1.

\section{FT-IR Spectroscopy}

The FT-IR spectrum of the ligandshowed bands at $3456,3379 \mathrm{~cm}^{-1}$ which refer to stretching vibration of $\mathrm{NH}_{2}$ [16]. The band of $v \mathrm{~N}-\mathrm{H}$ (amide) was appeared at $3205 \mathrm{~cm}^{-1}$ [16]. The spectrum of exhibited absence of carboxylic $\mathrm{OH}$ band (3300-2621 $\mathrm{cm}^{-1}$ in amoxicillin) and appear new band at $1342 \mathrm{~cm}^{-1}$, which due tov 0-B $[17,18]$. The spectrum showed band at $3525 \mathrm{~cm}^{-1}$ which was assigned to phenolic $\mathrm{OH}$ group [16]. The band of $v \mathrm{C}=0$ (carboxylic and $\beta$-lactam) was appeared at $1770 \mathrm{~cm}^{-1}[16,18]$. While the band of $v \mathrm{C}=0$ of amide appeared at $1683 \mathrm{~cm}^{-1}$ [16]. The data can be shown in Table 2. The spectra of complexes $\mathrm{C}_{1}, \mathrm{C}_{3}$, Mix.showed shifting in some band positions. The bands of $v \mathrm{NH}_{2}$ shifted to higher frequency of asymmetry bands and to lower frequency of symmetric bands (Table 2) and this refer to coordination with metal ions through the nitrogen atom of $\mathrm{NH}_{2}$ [4]. The band of $v \mathrm{NH}$ (amide) was shifted to higher frequency in all complexes and this is attributed to coordination with metal ions. The spectrum of mixed ligand showed a new band at $1560 \mathrm{~cm}^{-1}$ due to imine ( $v \mathrm{C}=\mathrm{N}$ ) [19]. All spectra of complexes exhibited new bands at lower frequency which refer tou M-O, v M-N and v M-Cl [20]. The data can be shown in Table 2.

\section{NMR Spectroscopy}

${ }^{1} \mathrm{HNMR}$ and ${ }^{13} \mathrm{CNMR}$ were used to characterized the ligand (L) and its metal complexes using $\mathrm{d}^{6}$-DMSO as solvent.

\section{${ }^{1}$ H-NMR Spectroscopy}

The spectra of all compounds showed peak at $\delta 2.5 \mathrm{ppm}$ which refer to chemical shift of DMSO as a solvent. The spectra of Lexhibited absence the proton peak of carboxylic $\mathrm{OH}$ (about $\delta 10 \mathrm{ppm}$ in amoxicillin) [21] and appear new proton peak of $\mathrm{B}-\mathrm{OH}$ at $\delta 8.74 \mathrm{pp}$ [22] (Table 3). The spectra of Co (II), $\mathrm{Ni}$ (II) and $\mathrm{Cu}$ (II) complexes $\left(\mathrm{C}_{1}-\mathrm{C}_{3}\right)$ were showed shifting to higher value in proton peak position of $\mathrm{N}-\mathrm{H}$ amide and $\mathrm{NH} 2$ groups (Tables 4-6) compartion with the spectrum of ligand (L) [21]. The spectrum of (Mix.) exhibited further proton peaks which attributed to 4-aminoantipyrine [19]. The spectrum of (Mix.) also showed shifting in position of chemical shift of $\mathrm{N}-\mathrm{H}$ amide and $\mathrm{NH}_{2}$ compartion with the ligand (Table 7) because the complexation with metal ions through nitrogen atoms of $\mathrm{N}-\mathrm{H}$ amide and $\mathrm{NH}_{2}$. The spectrum of (Mix.) also showed shifting to higher values in position peaks of $\mathrm{N}-\mathrm{CH}$ and this is because formation of imin group in neighbring atom [21]. The spectra of the ligand and $\mathrm{C}_{3}$ can be shown in Figs. 2-4.

\section{${ }^{13}$ CNMR Spectroscopy}

The ${ }^{13} \mathrm{CNMR}$ data are listed in (Tables 8-12). The chemical shift of DMSO as a solvent appeared at $\delta 40 \mathrm{ppm}$. The ${ }^{13} \mathrm{CNMR}$ spectrum of the ligand (L) showed shifted to higher values of carboxylic $\mathrm{C}=0$ group

Table 1: Analytical data and physical properties of the ligand and its metal complexes

\begin{tabular}{|c|c|c|c|c|c|c|c|c|c|c|c|}
\hline \multirow{2}{*}{ Comp. } & \multirow{2}{*}{$\begin{array}{l}\text { The molecular } \\
\text { formula }\end{array}$} & \multirow[t]{2}{*}{ Color } & \multirow[t]{2}{*}{ m.p $\left({ }^{\circ} \mathrm{C}\right)$} & \multirow{2}{*}{ Yield\% } & \multirow{2}{*}{$\begin{array}{l}\text { M.wt } \\
\text { g.mol- }\end{array}$} & \multicolumn{4}{|c|}{ Micro elementa analysis found (Calc.) } & \multirow{2}{*}{$\begin{array}{l}\text { Metal } \\
\text { content } \%\end{array}$} & \multirow{2}{*}{$\begin{array}{l}\text { Chloride } \\
\text { content } \%\end{array}$} \\
\hline & & & & & & $\mathrm{C} \%$ & H\% & N\% & S\% & & \\
\hline $\mathrm{L}$ & $\mathrm{C}_{16} \mathrm{H}_{20} \mathrm{~N}_{3} \mathrm{O}_{7} \mathrm{SB}$ & Yellow & $182-184$ & 51.54 & 408.82 & 46.39 (46.96) & $5.2(4.89)$ & $10.04(10.27)$ & $7.13(7.82)$ & -- & -- \\
\hline $\mathrm{C} 1$ & $\begin{array}{l}\mathrm{C}_{16}^{16} \mathrm{H}_{20} \mathrm{~N}_{3} \mathrm{O}_{7} \text { SBCo. } \\
2 \mathrm{Cl} .2 \mathrm{H}_{2} \mathrm{O}\end{array}$ & Green & $210-212$ & 42.85 & 574.73 & $33.21(33.41)$ & $4.43(4.18)$ & $7.21(7.31)$ & $5.48(5.56)$ & $10.13(10.25)$ & 12.12 \\
\hline $\mathrm{C} 2$ & $\begin{array}{l}\mathrm{C}_{16} \mathrm{H}_{20} \mathrm{~N}_{3} \mathrm{O}_{7} \mathrm{SBNi} . \\
2 \mathrm{Cl} .2 \mathrm{H}_{2} \mathrm{O}\end{array}$ & Brown & $240-242$ & 50.00 & 574.49 & $34.33(33.42)$ & $4.13(4.20)$ & $7.18(7.31)$ & $5.64(5.57)$ & $9.93(10.21)$ & $12.24(12.35)$ \\
\hline C3 & $\begin{array}{l}\mathrm{C}_{16} \mathrm{H}_{20} \mathrm{~N}_{3} \mathrm{O}_{7} \mathrm{SBCu} . \\
2 \mathrm{Cl} .2 \mathrm{H}_{2} \mathrm{O}\end{array}$ & Black & 140 Dec & 57.14 & 579.366 & $34.01(33.14)$ & $4.22(4.14)$ & $7.44(7.25)$ & $5.01(5.52)$ & $10.70(10.97)$ & 12.05 \\
\hline Mix. & $\begin{array}{l}\mathrm{C}_{27} \mathrm{H}_{31} \mathrm{~N}_{6} \mathrm{O}_{7} \mathrm{SBCu} . \\
2 \mathrm{Cl} .2 \mathrm{H}_{2} \mathrm{O}\end{array}$ & Black & $228-230$ & 52.08 & 764.36 & $42.39(42.38)$ & $4.32(4.57)$ & $10.62(10.98)$ & $4.22(4.18)$ & $8.12(8.31)$ & $8.99(9.28)$ \\
\hline
\end{tabular}

Dec: Decompose, M.wt: Molecular weight 
Table 2: Characteristic infrared absorption bands of the ligand and its metal complexes

\begin{tabular}{|c|c|c|c|c|c|c|c|c|c|c|c|}
\hline Comp & vNH2 & $\begin{array}{l}\text { vNH } \\
\text { amide }\end{array}$ & $\begin{array}{l}\text { vOH carboxylic. } \\
\text { Acid }\end{array}$ & $\begin{array}{l}\text { OH } \\
\text { phenolic }\end{array}$ & $\begin{array}{l}\text { vC=0 } \beta \text {-lactam and } \\
\text { carboxylic. Acid }\end{array}$ & $v C=0$ amide & vB-O & $v \mathbf{C}=\mathbf{N}$ & $v \mathbf{M}-\mathbf{0}$ & $v \mathbf{M}-\mathbf{N}$ & $v \mathbf{M}-\mathbf{C l}$ \\
\hline $\mathrm{L}$ & $\begin{array}{l}3456 \\
3379\end{array}$ & 3205 & ---- & 3525 & 1770 & 1683 & 1342 & ----- & ---- & ---- & ---- \\
\hline $\begin{array}{l}\mathrm{C} 1 \\
(\mathrm{Co})\end{array}$ & $\begin{array}{l}3471 \\
3350\end{array}$ & 3232 & ----- & 3527 & 1730 & 1645 & 1345 & ----- & 435 & 568 & 389 \\
\hline $\begin{array}{l}\mathrm{C} 2 \\
(\mathrm{Ni})\end{array}$ & $\begin{array}{l}3482 \\
3355\end{array}$ & 3235 & ----- & 3533 & 1750 & 1652 & 1346 & ----- & 438 & 565 & 362 \\
\hline Mix. & $\begin{array}{l}3482 \\
3355\end{array}$ & 3225 & ----- & 3523 & 1750 & 1652 & 1334 & 1560 & 536 & 449 & 366 \\
\hline
\end{tabular}

Table 3: 1HNMR data for the ligand

\begin{tabular}{ll}
\hline Assignments in d6-DMSO & Chemical shifts $\delta$ (ppm) \\
\hline OH Phenolic & $9.33(1 \mathrm{H}), \mathrm{s}$ \\
$\mathrm{B}-\mathrm{OH}$ & $8.74(2 \mathrm{H}), \mathrm{s}$ \\
$\mathrm{N}-\mathrm{H}$ Amide & $8.64(1 \mathrm{H}), \mathrm{s}$ \\
$\mathrm{C}-\mathrm{H}$ aromatic & $7.37-7.23(4 \mathrm{H}), \mathrm{m}$ \\
$\mathrm{CHNH}(\beta$-lactam) & $5.62(1 \mathrm{H}), \mathrm{d}$ \\
$\mathrm{CHS}(\beta$-lactam) & $5.32(1 \mathrm{H}), \mathrm{d}$ \\
$\mathrm{NH}_{2}$ & $4.98(2 \mathrm{H}), \mathrm{s}$ \\
$\mathrm{CH}-\mathrm{NH}_{2}$ & $4.98(1 \mathrm{H}), \mathrm{s}$ \\
$\mathrm{N}-\mathrm{CH}$ & $3.99(1 \mathrm{H}), \mathrm{s}$ \\
$2 \mathrm{CH}$ & $1.49(3 \mathrm{H}), \mathrm{s}, 1.40(3 \mathrm{H}), \mathrm{s}$ \\
\hline
\end{tabular}

DMSO: Dimethyl sulfoxide

Table 4: 1HNMR data for C1

\begin{tabular}{ll}
\hline Assignments in d6-DMSo & Chemical shifts $\delta$ (ppm) \\
\hline OH Phenolic & $9.20(1 \mathrm{H}), \mathrm{s}$ \\
$\mathrm{N}-\mathrm{H}$ Amide & $9.09(1 \mathrm{H}), \mathrm{s}$ \\
$\mathrm{B}-\mathrm{OH}$ & $8.83(2 \mathrm{H}), \mathrm{s}$ \\
$\mathrm{C}-\mathrm{H}$ aromatic & $8.03-6.50(4 \mathrm{H}), \mathrm{m}$ \\
$\mathrm{CHNH}(\beta$-lactam) & $5.69(1 \mathrm{H}), \mathrm{d}$ \\
$\mathrm{CHS}(\beta$-lactam) & $5.42(1 \mathrm{H}), \mathrm{d}$ \\
$\mathrm{NH}_{2}$ & $5.29(2 \mathrm{H}), \mathrm{s}$ \\
$\mathrm{CH}-\mathrm{NH}_{2}$ & $5.29(1 \mathrm{H}), \mathrm{s}$ \\
$\mathrm{N}-\mathrm{CH}$ & $3.96(1 \mathrm{H}), \mathrm{s}$ \\
$\mathrm{H}_{2} \mathrm{O}$ & $3.57(4 \mathrm{H}), \mathrm{s}$ \\
$2 \mathrm{CH}$ & $1.29(3 \mathrm{H}), \mathrm{s}, 1.16(3 \mathrm{H}), \mathrm{s}$ \\
\hline
\end{tabular}

DMSO: Dimethyl sulfoxide

Table 5: 1HNMR data for C2

\begin{tabular}{ll}
\hline Assignments in d6-DMSO & Chemical shifts $\delta$ (ppm) \\
\hline OH Phenolic & $9.26(1 \mathrm{H}), \mathrm{s}$ \\
$\mathrm{N}-\mathrm{H}$ Amide & $8.99(1 \mathrm{H}), \mathrm{s}$ \\
$\mathrm{B}-\mathrm{OH}$ & $8.85(2 \mathrm{H}), \mathrm{s}$ \\
$\mathrm{C}-\mathrm{H}$ aromatic & $8.02-6.50(4 \mathrm{H}), \mathrm{m}$ \\
$\mathrm{CHNH}(\beta$-lactam) & $5.70(1 \mathrm{H}), \mathrm{d}$ \\
$\mathrm{CHS}(\beta$-lactam) & $5.47(1 \mathrm{H}), \mathrm{d}$ \\
$\mathrm{NH}_{2}$ & $5.32(2 \mathrm{H}), \mathrm{s}$ \\
$\mathrm{CH}-\mathrm{NH}_{2}$ & $5.32(1 \mathrm{H}), \mathrm{s}$ \\
$\mathrm{N}-\mathrm{CH}$ & $3.99(1 \mathrm{H}), \mathrm{s}$ \\
$\mathrm{H}_{2} \mathrm{O}$ & $3.43(4 \mathrm{H}), \mathrm{s}$ \\
$2 \mathrm{CH}$ & $1.67(3 \mathrm{H}), \mathrm{s}, 1.38(3 \mathrm{H}), \mathrm{s}$ \\
\hline $\mathrm{DMSO}_{3}$ Dimethyl sulfoxide &
\end{tabular}

compartion with parent drug [23] and this is because the binding with $\mathrm{B}(\mathrm{OH})_{2}$. The spectra of metalcomplexes $\left(\mathrm{C}_{1}-\mathrm{C}_{3}\right)$ exhibited shifted to higher values in the chemical shift of $\mathrm{C}=0$ ( $\beta$-lactam $), \mathrm{C}=0$ amide and $\mathrm{CH}-\mathrm{NH}_{2}$ and this is attributed to complexation with metal ions [23]. In (Mix.) spectrum, the carboxylic $\mathrm{C}=\mathrm{O}$ band absent and appeared $\mathrm{a}$ new bands at $\delta 159.36$, which assigned to $\delta \mathrm{C}=\mathrm{N}$ (imino group) [19].

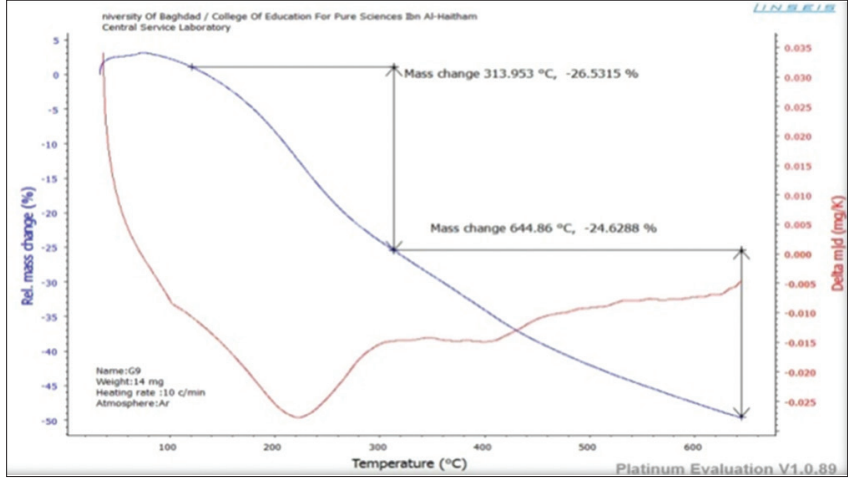

Fig. 2: The thermo gram of the Ligand

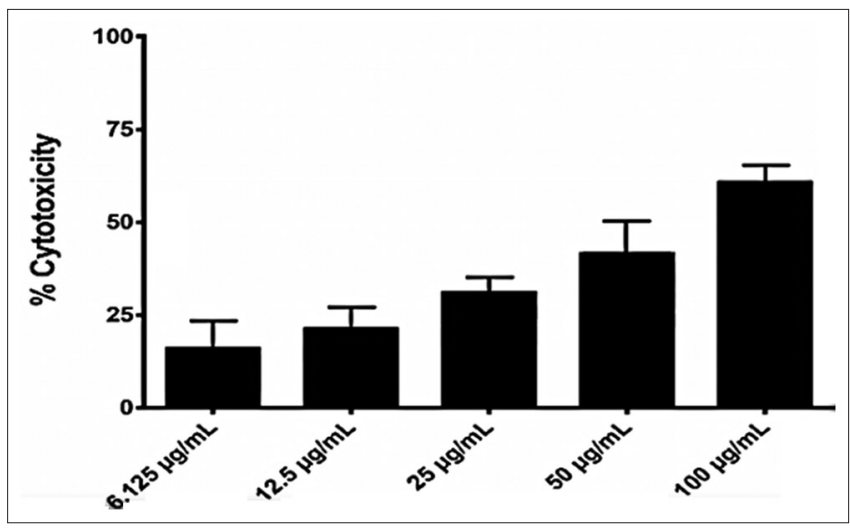

Fig. 3: Cytotoxic effect of $\left(C_{3}\right)$ in $A M J M$

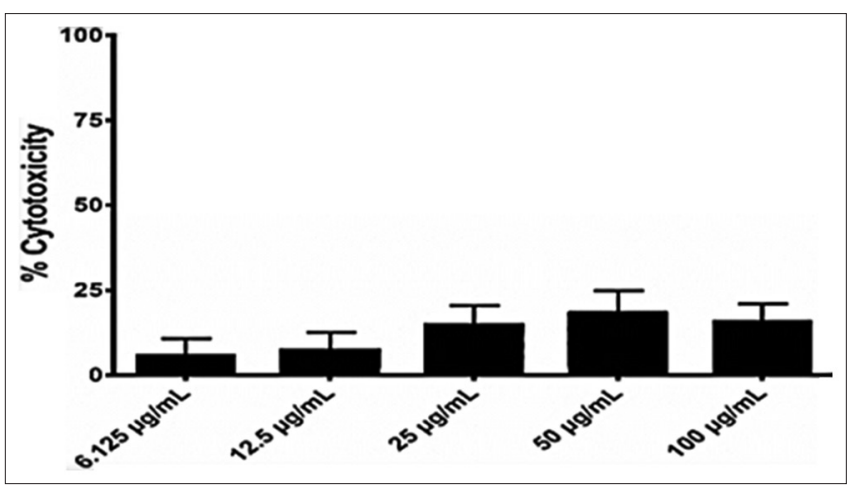

Fig. 4: Cytotoxic effect of (L) in SKOV-3

As well as the $\mathrm{C}=\mathrm{O}$ ( $\beta$-lactam), $\mathrm{C}=\mathrm{O}$ (amide) and $\mathrm{CH}-\mathrm{NH}_{2}$ bands were shifted to higher values and this is because coodination with metal ions. 
Electronic spectra

The electronic spectra of synthesized compounds were recorded in methanol $\left(10^{-4} \mathrm{M}\right)$ at room temperture. The spectral data were listed in Table 13. The electronic spectrum of ligand exhibited high intensity band in $356 \mathrm{~nm}\left(28089 \mathrm{~cm}^{-1}\right)$, which due to $\pi \rightarrow \pi^{*}$ transition [24]. In addition the spectrum of ligand showed low intensity bands at $373 \mathrm{~nm}\left(26809 \mathrm{~cm}^{-1}\right)$, which assigned to $\mathrm{n} \rightarrow \pi^{*}$ transition [24]. The data were listed in Table 13. The spectrum of $\mathrm{C}_{1}$ complex showed change in position of $\pi \rightarrow \pi^{*}$ transition (Table 14). The spectrum of $\mathrm{C}_{1}$ complex exhibited two bands appeared at $585 \mathrm{~nm}$ $\left(17049 \mathrm{~cm}^{-1}\right)$ and $805 \mathrm{~nm}\left(12422 \mathrm{~cm}^{-1}\right)$ which assigned to ${ }^{4} \mathrm{~T}_{1} \mathrm{~g} \rightarrow{ }^{4} \mathrm{~T}_{1} \mathrm{~g}$ (p) and ${ }^{4} \mathrm{~T}_{1} \mathrm{~g} \rightarrow{ }^{4} \mathrm{~A}_{2} \mathrm{~g}$ respectively [25]. The magnetic moment valueof $\mathrm{C}_{1}$ complex were found (Meff= 4.55 B.M) and this value is agreement with octahedral geometry [25]. The data were listed in Table 14. The spectrum of Ni (II) complexexhibited change in $\pi \rightarrow \pi^{*}$ transition. The spectrum of $\mathrm{Ni}$ (II) complex showed two bands at $610 \mathrm{~nm}$ (16393 $\left.\mathrm{cm}^{-1}\right)$ and $951 \mathrm{~nm}\left(10515 \mathrm{~cm}^{-1}\right)$ which due to ${ }^{3} \mathrm{~A}_{2} \mathrm{~g} \rightarrow{ }^{3} \mathrm{~T}_{1} \mathrm{~g}(\mathrm{~F})$ and ${ }^{3} \mathrm{~A}_{2} \mathrm{~g}$ $\rightarrow{ }^{3} \mathrm{~T}_{2} \mathrm{~g}$ transition of octahedral Ni (II) complexes $[25,26]$. The Meff of nickel $\mathrm{C}_{2}$ were 3.42 B.M. This value agreement with octahedral

Table 6: 1HNMR data for $\mathrm{C} 3$

\begin{tabular}{ll}
\hline Assignments in d6-DMSo & Chemical shifts $\delta$ (ppm) \\
\hline OH Phenolic & $9.35(1 \mathrm{H}), \mathrm{s}$ \\
$\mathrm{N}-\mathrm{H}$ Amide & $9.08(1 \mathrm{H}), \mathrm{s}$ \\
$\mathrm{B}-\mathrm{OH}$ & $8.75(1 \mathrm{H}), \mathrm{s}$ \\
$\mathrm{C}-\mathrm{H}$ aromatic & $8.03-6.74(4 \mathrm{H}), \mathrm{m}$ \\
$\mathrm{CHNH}(\beta$-lactam) & $5.76(1 \mathrm{H}), \mathrm{d}$ \\
$\mathrm{CHS}(\beta$-lactam) & $5.35(2 \mathrm{H}), \mathrm{s}$ \\
$\mathrm{NH}_{2}$ & $5.20(2 \mathrm{H}), \mathrm{s}$ \\
$\mathrm{CH}-\mathrm{NH}_{2}$ & $5.20(1 \mathrm{H}), \mathrm{s}$ \\
$\mathrm{N}-\mathrm{CH}$ & $3.94(1 \mathrm{H}), \mathrm{s}$ \\
$\mathrm{H}_{2} \mathrm{O}$ & $3.36(4 \mathrm{H}), \mathrm{s}$ \\
$2 \mathrm{CH}$ & $1.55(3 \mathrm{H}), \mathrm{s}, 1.40(3 \mathrm{H}), \mathrm{s}$ \\
\hline
\end{tabular}

DMSO: Dimethyl sulfoxide

Table 7: 1HNMR data for mix

\begin{tabular}{ll}
\hline Assignments in d6-DMSO & Chemical shifts $\delta$ (ppm) \\
\hline OH Phenolic & $9.41(1 \mathrm{H}), \mathrm{s}$ \\
$\mathrm{N}-\mathrm{H}$ Amide & $9.04(1 \mathrm{H}), \mathrm{s}$ \\
$\mathrm{B}-\mathrm{OH}$ & $8.68(2 \mathrm{H}), \mathrm{s}$ \\
$\mathrm{C}-\mathrm{H}$ aromatic & $7.87-6.55(9 \mathrm{H}), \mathrm{m}$ \\
$\mathrm{CHNH}(\beta$-lactam) & $5.76(\mathrm{IH}), \mathrm{d}$ \\
$\mathrm{CHS}(\beta$-lactam) & $5.36(1 \mathrm{H}), \mathrm{d}$ \\
$\mathrm{NH}_{2}$ & $5.29(2 \mathrm{H}), \mathrm{s}$ \\
$\mathrm{CH}-\mathrm{NH}_{2}$ & $5.29(1 \mathrm{H}), \mathrm{s}$ \\
$\mathrm{N}-\mathrm{CH}$ & $4.32(1 \mathrm{H}), \mathrm{s}$ \\
$\mathrm{H}_{2} \mathrm{O}$ & $3.40(4 \mathrm{H}), \mathrm{s}$ \\
$\mathrm{N}_{-}-\mathrm{CH}_{3}$ & $3.40(3 \mathrm{H}), \mathrm{s}$ \\
$\mathrm{C}-\mathrm{CH}_{3}$ & $2.50(3 \mathrm{H}), \mathrm{s}$ \\
$2 \mathrm{CH}_{3}$ & $1.63(3 \mathrm{H}), \mathrm{s}, 1.51(3 \mathrm{H}), \mathrm{s}$ \\
\hline
\end{tabular}

DMSO: Dimethyl sulfoxide

Table 8: 13CNMR data for the Ligand

\begin{tabular}{ll}
\hline Assignments in d6-DMSO & Chemical shifts $\delta$ (ppm) \\
\hline COOB & 173.36 \\
$\mathrm{C}=\mathrm{O}(\beta$-lactam) & 170.16 \\
$\mathrm{C}=\mathrm{O}$ (amide) & 169.15 \\
$\mathrm{C}$ (heterocyclic ring) & 139.92 \\
Aromatic carbon & $130.30-112.80$ \\
CHNH $(\beta$-lactam) & 61.17 \\
$\mathrm{CHS}(\beta$-lactam) & 58.96 \\
$\mathrm{CH}-\mathrm{NH}_{2}$ & 57.84 \\
$\mathrm{C}-\mathrm{S}$ & 26.51 \\
$2 \mathrm{CH}$ & $20.30,18.15$ \\
\hline
\end{tabular}

geometry [25-27]. The data were listed in Table 13.The spectra of copper complexes $\left(\mathrm{C}_{3}\right.$ and Mix.) complexes showed change in $\pi \rightarrow \pi^{*}$ transition (Table 14). The spectrum of $\mathrm{C}_{3}$ complex showed three bands at $541 \mathrm{~nm}\left(18484 \mathrm{~cm}^{-1}\right), 651 \mathrm{~nm}\left(15360 \mathrm{~cm}^{-1}\right)$ and $761 \mathrm{~nm}(13140$ $\mathrm{cm}^{-1}$ ) which due to ${ }^{2} \mathrm{~B}_{1} \mathrm{~g} \rightarrow{ }^{2} \mathrm{Eg},{ }^{2} \mathrm{~B}_{1} \mathrm{~g} \rightarrow{ }^{2} \mathrm{~B}_{2} \mathrm{~g}$ and ${ }^{2} \mathrm{~B}_{1} \mathrm{~g} \rightarrow{ }^{2} \mathrm{~A}_{1} \mathrm{~g}$ transitions (Table 14) of distorted octahedral copper complexes [25] (Fig. 5). The spectrum of mixed ligand complex (Mix.) (Fig. 6) exhibited one

Table 9: ${ }^{13} \mathrm{CNMR}$ data for $\mathrm{C} 1$

\begin{tabular}{ll}
\hline Assignments in d6-DMSO & Chemical shifts $\delta$ (ppm) \\
\hline $\mathrm{C}=\mathrm{O}(\beta$-lactam) & 177.33 \\
$\mathrm{C}=\mathrm{O}($ amide $)$ & 175.50 \\
$\mathrm{COOB}$ & 173.70 \\
$\mathrm{C}$ (heterocyclic ring) & 140.40 \\
Aromatic carbon & $130.24-113.38$ \\
$\mathrm{CH}-\mathrm{NH}_{2}$ & 64.39 \\
$\mathrm{CHNH}(\beta$-lactam) & 61.53 \\
$\mathrm{CHS}(\beta$-lactam) & 59.39 \\
$\mathrm{C}-\mathrm{S}$ & 25.51 \\
$2 \mathrm{CH}$ & $17.58,16.35$ \\
\hline
\end{tabular}

Table 10: ${ }^{13}$ CNMR data for $\mathrm{C} 2$

\begin{tabular}{ll}
\hline Assignments in d6-DMSo & Chemical shifts $\delta$ (ppm) \\
\hline $\mathrm{C}=\mathrm{O}(\beta$-lactam $)$ & 176.63 \\
$\mathrm{C}=\mathrm{O}($ amide) & 175.43 \\
$\mathrm{COOB}$ & 173.72 \\
$\mathrm{C}($ heterocyclic ring) & 137.54 \\
Aromatic carbon & $133.55-115.18$ \\
$\mathrm{CH}-\mathrm{NH}_{2}$ & 64.37 \\
$\mathrm{CHNH}(\beta$-lactam $)$ & 62.75 \\
$\mathrm{CHS}(\beta$-lactam) & 58.50 \\
$\mathrm{C}-\mathrm{S}$ & 26.82 \\
$2 \mathrm{CH}$ & $18.48,15.83$ \\
\hline
\end{tabular}

Table 11: ${ }^{13} \mathrm{CNMR}$ data for C3

\begin{tabular}{ll}
\hline Assignments in d6-DMSO & Chemical shifts $\delta$ (ppm) \\
\hline $\mathrm{C}=\mathrm{O}(\beta$-lactam) & 176.22 \\
$\mathrm{C}=\mathrm{O}$ (amide) & 174.52 \\
$\mathrm{COOB}$ & 173.18 \\
$\mathrm{C}$ (heterocyclic ring) & 138.54 \\
Aromatic carbon & $132.84-112.13$ \\
$\mathrm{CH}-\mathrm{NH}_{2}$ & 63.35 \\
$\mathrm{CHNH}(\beta$-lactam) & 62.79 \\
$\mathrm{CHS}(\beta$-lactam) & 58.53 \\
$\mathrm{C}-\mathrm{S}$ & 26.88 \\
$2 \mathrm{CH}$ & $20.87,18.18$ \\
\hline
\end{tabular}

Table 12: ${ }^{13}$ CNMR data for Mix

\begin{tabular}{ll}
\hline Assignments in d6-DMSo & Chemical shifts $\delta$ (ppm) \\
\hline $\mathrm{C}=\mathrm{O}(\beta$-lactam) & 176.71 \\
$\mathrm{C}=\mathrm{O}$ (amide) & 175.35 \\
$\mathrm{C}=\mathrm{N}, \mathrm{C}=\mathrm{O}$ (4-aminoantipyrine) & 159.36 \\
$\mathrm{C}$ (heterocyclic ring) & 140.43 \\
$\mathrm{C}(4$-aminoantipyrine) & 134.54 \\
Aromatic carbon & $134.54-110.27$ \\
$\mathrm{C}-\mathrm{N}(4$-aminoantipyrine) & 115.72 \\
$\mathrm{CH}-\mathrm{NH}_{2}$ & 66.31 \\
$\mathrm{C}(\beta$-lactam) & 63.53 \\
$\mathrm{C}(\beta$-lactam) & 57.94 \\
$\mathrm{~N}-\mathrm{CH}$ & 39.08 \\
$\mathrm{C}-\mathrm{S}$ & 23.57 \\
$2 \mathrm{CH}$ & $21.69,18.37$ \\
$\mathrm{CH}_{3}(4$-aminoantipyrine) & 18.37 \\
\hline
\end{tabular}


Table 13: Electronic transitions, molar conductivity, spectra, magnetic susceptibility and suggested geometry of the ligand and its metal complexes

\begin{tabular}{|c|c|c|c|c|c|}
\hline Comp & Band positions $\mathrm{nm}\left(\mathrm{cm}^{-1}\right)$ & Assignment & Molar conductivity $\left(\mathrm{S} . \mathrm{cm}^{2} \cdot \mathrm{mol}^{-1}\right)$ in Methanol & $\mu$ eff. (B.M) & Suggested geometry \\
\hline \multirow[t]{2}{*}{$\mathrm{L}$} & $356(28089)$ & $\left(\pi \rightarrow \pi^{*}\right)$ & ----- & ----- & ----- \\
\hline & $370(27027)$ & $\left(\mathrm{n} \rightarrow \pi^{*}\right)$ & & & \\
\hline \multirow[t]{3}{*}{$\mathrm{C} 1$} & $363(27548)$ & $\left(\pi \rightarrow \pi^{*}\right)$ & 25 & 4.55 & Octahedral \\
\hline & $585(17094)$ & ${ }^{4} \mathrm{~T}_{1} \mathrm{~g} \rightarrow{ }^{4} \mathrm{~T}_{1} \mathrm{~g}(\mathrm{P})$ & & & \\
\hline & $805(12422)$ & ${ }^{4} \mathrm{~T}_{1} \mathrm{~g} \rightarrow{ }^{4} \mathrm{~A}_{2} \mathrm{~g}$ & & & \\
\hline \multirow[t]{3}{*}{$\mathrm{C} 2$} & $351(28490)$ & $\left(\pi \rightarrow \pi^{*}\right)$ & 23 & 3.42 & Octahedral \\
\hline & $610(16393)$ & ${ }^{3} \mathrm{~A}_{2} \mathrm{~g} \rightarrow{ }^{3} \mathrm{~T}_{1} \mathrm{~g}(\mathrm{~F})$ & & & \\
\hline & $951(10515)$ & ${ }^{3} \mathrm{~A}_{2} \mathrm{~g} \rightarrow{ }^{3} \mathrm{~T}_{2} \mathrm{~g}$ & & & \\
\hline \multirow[t]{4}{*}{$\mathrm{C} 3$} & $363(27548)$ & $\left(\pi \rightarrow \pi^{*}\right)$ & 30 & 1.96 & distorted octahedral \\
\hline & $541(18484)$ & ${ }^{2} \mathrm{~B}_{1} \mathrm{~g} \rightarrow{ }^{2} \mathrm{Eg}$ & & & \\
\hline & $651(15360)$ & ${ }^{2} \mathrm{~B}_{1} \mathrm{~g} \rightarrow{ }^{2} \mathrm{~B}_{2} \mathrm{~g}$ & & & \\
\hline & $761(13140)$ & ${ }^{2} \mathrm{~B}_{1} \mathrm{~g} \rightarrow{ }^{2} \mathrm{~A}_{1} \mathrm{~g}$ & & & \\
\hline \multirow[t]{2}{*}{ Mix. } & $363(27548)$ & $\left(\pi \rightarrow \pi^{*}\right)$ & 42 & 1.89 & distorted octahedral \\
\hline & $758(13192)$ & ${ }^{2} \mathrm{~B}_{1} \mathrm{~g} \rightarrow{ }^{2} \mathrm{~A}_{1} \mathrm{~g}$ & & & \\
\hline
\end{tabular}

Table 14: Thermal decomposition data of the ligand (L) and its metal complexes

\begin{tabular}{|c|c|c|c|c|c|c|}
\hline \multirow{3}{*}{$\begin{array}{l}\begin{array}{l}\text { Molecular formula } \\
\text { and Molecular weight }\end{array} \\
\mathrm{C}_{16} \mathrm{H}_{20} \mathrm{~N}_{3} \mathrm{O}_{7} \mathrm{SB}\end{array}$} & \multirow{3}{*}{$\begin{array}{l}\text { Step } \\
1\end{array}$} & \multirow{3}{*}{$\begin{array}{l}\text { Temp. rang of the } \\
\text { Decomposition } \mathrm{C}^{\circ}\end{array}$} & \multirow{3}{*}{$\begin{array}{l}\text { DTG Temp C } \\
101,225\end{array}$} & \multirow{3}{*}{$\begin{array}{l}\text { Suggested } \\
\text { Formula of loss } \\
\mathrm{H}_{2} \mathrm{BO}_{2}, 2 \mathrm{CH}_{2}, \mathrm{OH}\end{array}$} & \multirow{2}{*}{\multicolumn{2}{|c|}{$\begin{array}{l}\text { Mass loss \% } \\
\text { Cal. Found }\end{array}$}} \\
\hline & & & & & & \\
\hline & & & & & 26.36 & 26.53 \\
\hline 408.82 & Residue & $>650$ & & $\mathrm{HO}\left(\mathrm{C}_{6} \mathrm{H}_{4}\right) \mathrm{CHCONH}\left(\mathrm{C}_{3} \mathrm{H}_{2} \mathrm{NO}\right)$ & 48.92 & 48.85 \\
\hline $\mathrm{C}_{16} \mathrm{H}_{20} \mathrm{~N}_{3} \mathrm{O}_{7}$ SBCo. & 1 & $40-184.70$ & 55,100 & $2 \mathrm{H}_{2} \mathrm{O}, \mathrm{OH}$ & 9.22 & 9.2 \\
\hline 2Cl. $2 \mathrm{H}_{2} \mathrm{O}$ & 2 & $184.70-272.07$ & 235 & $2 \mathrm{Cl}, \mathrm{OH}, \mathrm{CH}_{3}$ & 17.92 & 17.9 \\
\hline \multirow[t]{2}{*}{$574.73^{2}$} & 3 & $272.07-642.59$ & $300,330,450,595,625$ & $(\mathrm{HO}) \mathrm{C}_{6} \mathrm{H}_{4} \mathrm{CH}\left(\mathrm{NH}_{2}\right) \mathrm{CO}, \mathrm{CH}_{3}$ & 28.71 & 28.83 \\
\hline & Residue & $>650$ & & NHCH (CO) CH (N) SCCHCOOBCo & 44.14 & 44.07 \\
\hline $\mathrm{C}_{16} \mathrm{H}_{20} \mathrm{~N}_{3} \mathrm{O}$ - SB & 1 & $16-189.13$ & $27,50,100,120,166$ & $\mathrm{H}_{2} \mathrm{O}$ & 3.13 & 3.64 \\
\hline Ni. 2 Cl. $2 \mathrm{H}_{2} \mathrm{O}$ & 2 & $189.13-259.07$ & 227 & $\mathrm{H}_{2} \mathrm{O}, 2 \mathrm{Cl}$ & 15.49 & 15.96 \\
\hline \multirow[t]{2}{*}{574.49} & 3 & $259.07-644.69$ & $\begin{array}{l}275,318,400,475,558, \\
583,633\end{array}$ & $\mathrm{SC}\left(\mathrm{CH}_{3}\right)_{2} \mathrm{CHCOOB}(\mathrm{OH})_{2}$ & 30.6 & 30.83 \\
\hline & Residue & $>650$ & & $\begin{array}{l}\mathrm{HO}\left(\mathrm{C}_{6} \mathrm{H}_{4}\right) \mathrm{CH}\left(\mathrm{NH}_{2}\right) \\
\mathrm{CONH}\left(\mathrm{C}_{3} \mathrm{H}_{2} \mathrm{NO}\right) \mathrm{Ni}\end{array}$ & 50.77 & 49.57 \\
\hline $\mathrm{C}_{16} \mathrm{H}_{20} \mathrm{~N}_{3} \mathrm{O}_{7} \mathrm{SBCu}$ & 1 & $25-258.56$ & $45,85,100$ & $2 \mathrm{H}_{2} \mathrm{O}, \mathrm{H}_{2} \mathrm{BO}_{2}$ & 13.94 & 13.92 \\
\hline 579.36 & Residue & $>650$ & & $\begin{array}{l}\left(\mathrm{C}_{6} \mathrm{H}_{4}\right) \mathrm{CHCONHCH}(\mathrm{CO}) \mathrm{CH}(\mathrm{S}) \\
(\mathrm{N}) \mathrm{Cu}\end{array}$ & 51.01 & 51.29 \\
\hline \multirow{6}{*}{$\begin{array}{l}\mathrm{C}_{27} \mathrm{H}_{31} \mathrm{~N}_{6} \mathrm{O}_{7} \mathrm{SB} \\
\mathrm{Cu} .2 \mathrm{Cl} .2 \mathrm{H}_{2} \mathrm{O} \\
764.36\end{array}$} & 1 & $25-161.83$ & $40,75,100,120$ & $2 \mathrm{H}_{2} \mathrm{O}, 2 \mathrm{CH}_{3}$ & 8.63 & 7.95 \\
\hline & 2 & $161.83-230.82$ & 187 & $2 \mathrm{Cl}, \mathrm{OH}$ & 11.51 & 11.53 \\
\hline & 3 & $230.82-360.37$ & 285,345 & $\begin{array}{l}\mathrm{C}=\mathrm{C}\left(\mathrm{CH}_{3}\right) \mathrm{N}\left(\mathrm{CH}_{3}\right) \mathrm{N}\left(\mathrm{C}_{6} \mathrm{H}_{5}\right) \mathrm{CO}, \mathrm{SC}, \\
2 \mathrm{OH}\end{array}$ & 34.66 & 34.97 \\
\hline & 4 & $360.37-494.13$ & 405,457 & $\left(\mathrm{C}_{6} \mathrm{H}_{4}\right) \mathrm{CHNH}_{2}$ & 13.73 & 13.61 \\
\hline & 5 & $494.13-643.86$ & $535,570,610$ & CONHCHCHNCHC (N) OB & 19.46 & 19.31 \\
\hline & Residue & $>650$ & & $\mathrm{COCu}$ & 11.98 & 12.63 \\
\hline
\end{tabular}

Table 15: The biological activity for compounds in $10^{-2}$ and $10^{-3} \mathrm{M}$

\begin{tabular}{|c|c|c|c|c|c|c|}
\hline \multirow[t]{2}{*}{ Compound } & \multicolumn{2}{|c|}{$\begin{array}{l}\text { P. auroginosa } \\
\text { Inhibition zone } \\
\text { diameter (mm) }\end{array}$} & \multicolumn{2}{|c|}{$\begin{array}{l}\text { S. aureus } \\
\text { Inhibition zone } \\
\text { diameter (mm) }\end{array}$} & \multicolumn{2}{|c|}{$\begin{array}{l}\text { E. coli } \\
\text { Inhibition zone } \\
\text { diameter (mm) }\end{array}$} \\
\hline & $10^{-2}$ & $10^{-3}$ & $10^{-2}$ & $10^{-3}$ & $10^{-2}$ & $10^{-3}$ \\
\hline DMSO & _- & - & _- & _- & - & - \\
\hline Amoxicillin & - & 14 & 14 & - & 15 & 15 \\
\hline Boric acid & - & _- & 12 & 14 & _- & _- \\
\hline $\mathrm{L}$ & - & - & 14 & 12 & & $\overline{11}$ \\
\hline $\mathrm{C} 1$ & 11 & - & 15 & 11 & 11 & 13 \\
\hline $\mathrm{C} 2$ & 13 & - & 14 & 11 & 13 & 11 \\
\hline C3 & 19 & $\overline{10}$ & 28 & 12 & 18 & 18 \\
\hline Mix. & 17 & 7 & 30 & 11 & 17 & 17 \\
\hline
\end{tabular}

E. coli: Escherichia coli, P. auroginosa: Pseudomonas auroginosa

band at $758 \mathrm{~nm}\left(13192 \mathrm{~cm}^{-1}\right)$, this band due to ${ }^{2} \mathrm{~B}_{1} \mathrm{~g} \rightarrow{ }^{2} \mathrm{~A}_{1} \mathrm{~g}$ transition of distorted octahedral $\mathrm{Cu}$ (II) complex [25] (Fig. 7). The magnetic moment of copper complexes were 1.96 and 1.89 B.M of $\mathrm{C}_{3}$ and

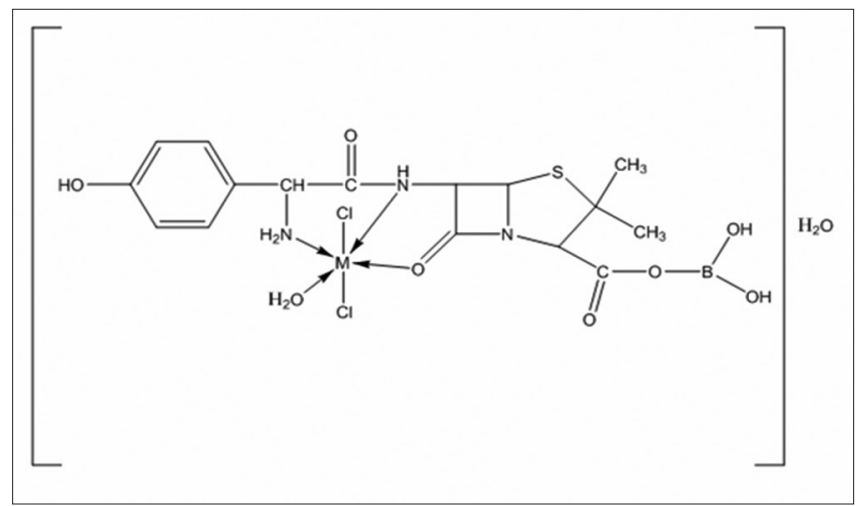

Fig. 5: Structure of the complex $\left(\mathrm{C}_{1}, \mathrm{C}_{2}\right.$ and $\left.\mathrm{C}_{3}\right)$

Mix. respectively, these values of Meff agreement with distorted octahedral geometry [25]. All complexes exhibited a nonelectrolyte behavior [28] (Table 13). 
Thermal analysis of the ligand and its metal complexes

The TG and DTG analysis were performed under nitrogen gas in the range heating $16-650^{\circ} \mathrm{C}$ and the heating rate $\left(10^{\circ} \mathrm{C} / \mathrm{min}\right)$. This technique was used to study the thermal stability of synthesized compounds as well as to characterize the suggested structures. The thermal decomposition data were listed in (Table 14) and the thermographs of the ligand (L) and $\mathrm{C}_{1}$ complex were shown in (Figs. 2 and 8). The results showed that the stability of the ligand and its complexes was increase as the following order Mix. $<\mathrm{C}_{1}<\mathrm{L}_{1}<\mathrm{C}_{2}<\mathrm{C}_{3}$. The results of degradation exhibited good agreement in percentage of calculate and found mass loss and this confirm the suggested structures of synthesized compounds [29].

\section{Biological activity}

The antibacterial activity of the ligand (L) and its metal complexes have been evaluated against ( $P$. auroginosa, E. coli (G-) and

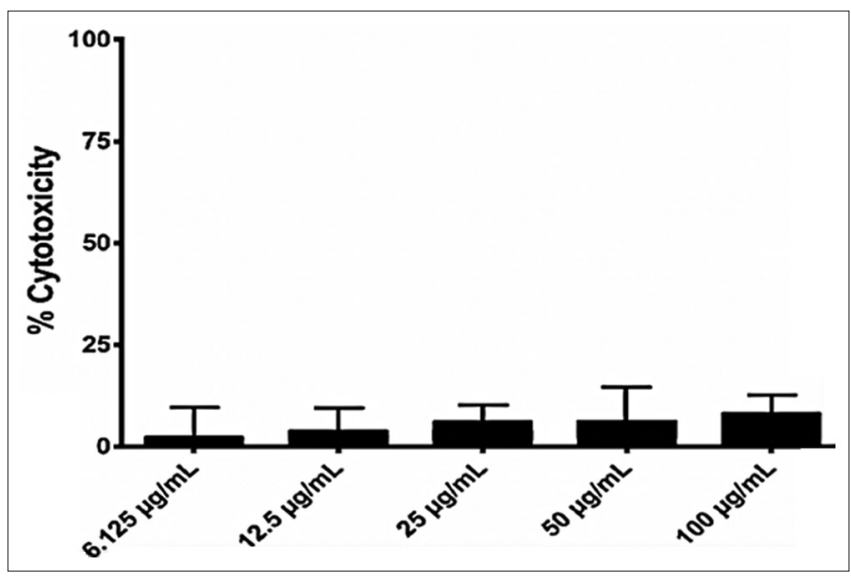

Fig. 6: Cytotoxic effect of (L) in CMF-7

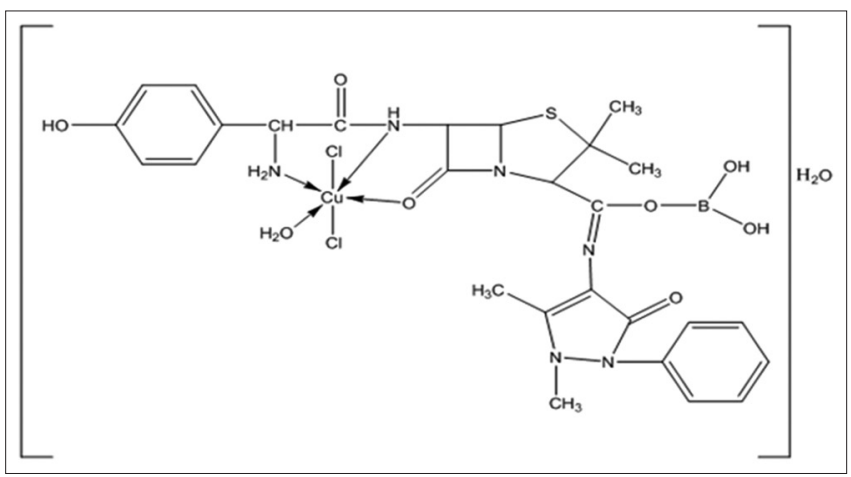

Fig. 7: Structure of the complexe (Mix.) M= Co (II), Ni (II) and Cu (II)

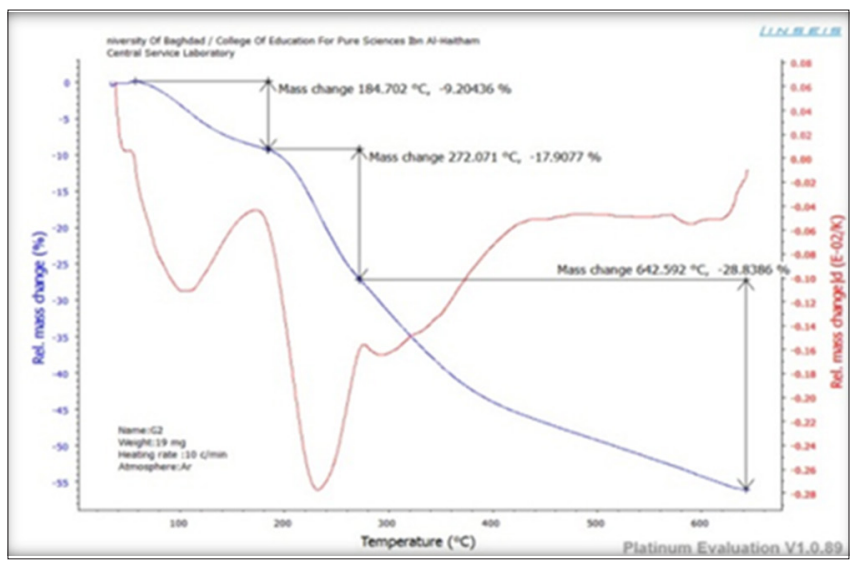

Fig. 8: The thermogram of the cobalt complex $\left(C_{1}\right)$
Staphylococcus aureus $(\mathrm{G}+))$. The bacterial activity was test with two concentration $\left(10^{-2}\right.$ and $\left.10^{-3} \mathrm{M}\right)$ of the primary materials and all synthesized compounds. The $\mathrm{C}_{3}$ and Mix. in $10^{-2} \mathrm{M}$ were the most effective against the studied microorganism. The ligand (L) exhibited small activity with $S$. aureus compartion with its complexes. All synthesized compounds in $10^{-3} \mathrm{M}$ were more active from the parint drug against $S$. aureus. The antibacterial data were listed in (Table 15). DMSO solvent was used as control [30].

\section{Hepatoprotective and kidney evaluation}

Hepatoprotective evaluations included assessment of liver function enzyme (GOT, GPT and ALP) and renal function test (Urea, Creatinine, TSP and Alb) in serum. The results were listed in (Tables 16 and 17). The obtained results showed the positive effect of all studied compound on GOT, GPT, ALP, Urea, Creatinine, TSP and Alb.

\section{Histopathological evaluation}

The results of histopathological evaluation of liver and kidney tissue which treated with $\mathrm{C}_{3}$ and Mix. showed the positive effect

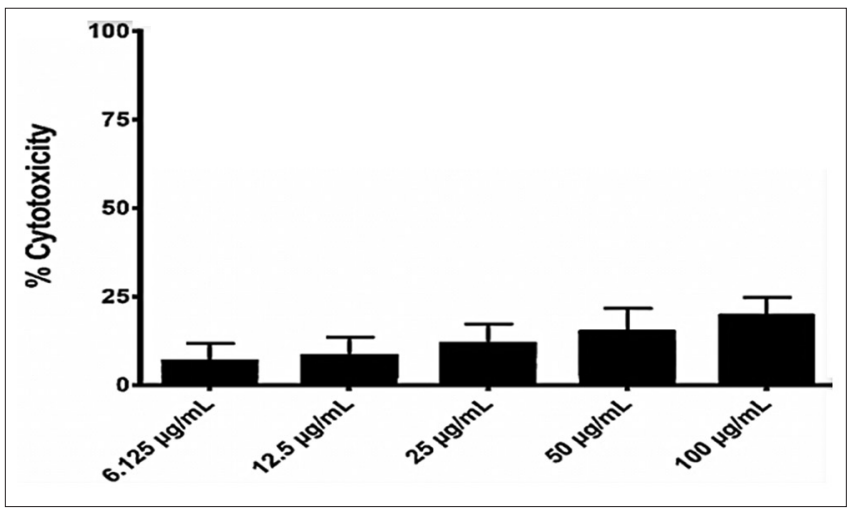

Fig. 9: Cytotoxic effect of ligand (L) in AMJM

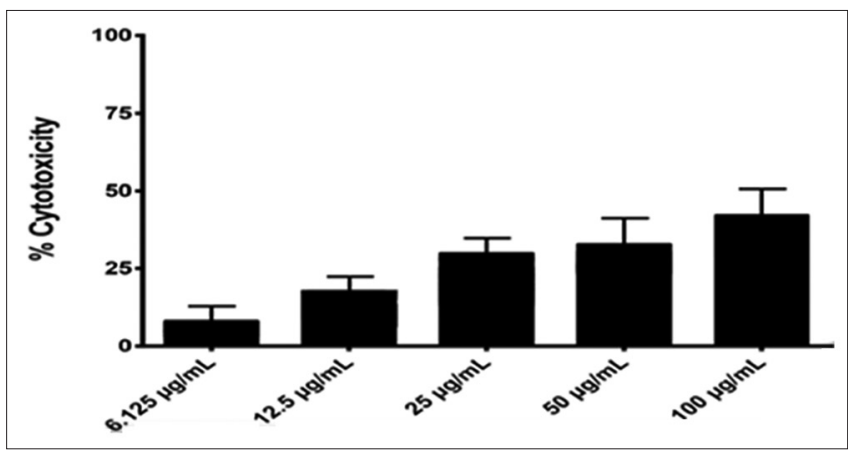

Fig. 10: Cytotoxic effect of $\left(C_{3}\right)$ in SKOV-3

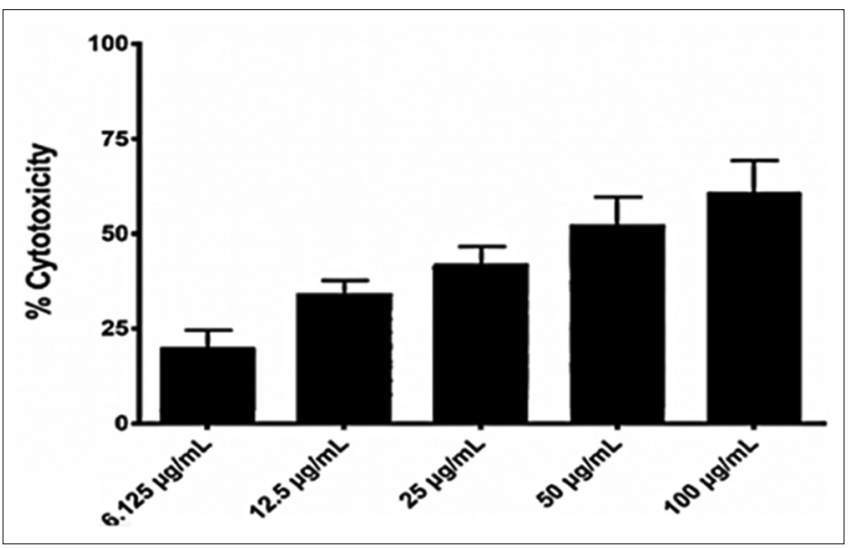

Fig. 11: Cytotoxic effect of (Mix.) in CMF-7 
of studied compounds and no negative effect were on tissue observed.

\section{Anticancer activity (cytotoxicity assays)}

Study of anticancer activity for amoxicillin, $\mathrm{L}, \mathrm{C}_{3}$ and Mix. was carried out on different cancer cell lines (AMJM, SOK-7 and CMF-3). The inhibition rate of cell growth (the percentage of cytotoxicity) was calculated as the following equation:

$$
\text { Inhibition rate }=\frac{A-B}{A} \times 100
$$

Where A and B are the optical density of control and the optical density of test.

The study of anticancer activity for the ligand exhibited high percentage of cytotoxicity comparison with amoxicillin, this is due to presence of boron element and this is agreement with literature [31]. The increase in percentage of cell inhibition due to presence of $\beta$-lactam ring in all studied compounds as well as presence of aromatic ring in Mix. (4-Aminoamtipyrine) and this is enhanced the anticancer activity [32]. Also found that the Schiff base ligand improve the anticancer activity [33]. The Schiff base linkage $(-\mathrm{C}=\mathrm{N})$ is an essential structural requirement for antitumor activities [33, 34].Cytotoxicity assays of ligand and its complexes are shown in Tables 18-20 and Figs. 9-11 for L and $\mathrm{C}_{3}$.

DPPH radical scavenging activity (RSA)(antioxidant activity) 2,2-diphenyl-1-picryl-hydrazyl (DPPH) was used in RSA for the evaluation of antioxidant and this is the rapid technique for screening the RSA of specific compounds or extracts [35]. DPPH is a stable free radical that can accept an electron or hydrogen radical and get converted to a stable, diamagnetic molecule. The results of this study showed that the ligand exhibited a negligible DPPH activity. In

Table 16: Effect of the Ligand (L) and its metal complexes on liver function enzymes (GOT, GPT and ALP) in sera of albino male mice

\begin{tabular}{llll}
\hline Groups & Dose (mg/Kg) & $\begin{array}{l}\text { GOT (Mean+Standard } \\
\text { error of mean) }\end{array}$ & $\begin{array}{l}\text { GPT (Mean+Standard } \\
\text { error of mean) }\end{array}$ \\
\hline Control & 0.625 & $38.50 \pm 0.50$ & $\begin{array}{l}\text { ALP (Mean+Standard } \\
\text { error of mean) }\end{array}$ \\
L & 0.625 & $21.00 \pm 1.00$ & $50.50 \pm 2.50$ \\
C3 & 0.625 & $27.50 \pm 0.50$ & $35.50 \pm 1.50$ \\
Mix. & 0.625 & $42.00 \pm 1.50$ & $50.00 \pm 2.50$ \\
\hline
\end{tabular}

GOT: Glutamic oxaloacetic transaminase, GPT: Glutamate pyruvate transaminase, ALP: Alkaline phosphatase

Table 17: Effect of the Ligand (L) and its Metal Complexeson Renal Function Test (Urea, Creatinine, Alb and TSP) in Sera of Albino Male Mice

\begin{tabular}{|c|c|c|c|c|c|}
\hline Groups & Dose (mg/Kg) & $\begin{array}{l}\text { Urea (Mean } \pm \text { Standard } \\
\text { error of mean) }\end{array}$ & $\begin{array}{l}\text { Creatinine (Mean } \pm \text { Standard } \\
\text { error of mean) }\end{array}$ & $\begin{array}{l}\text { Alb (Mean } \pm \text { Standard } \\
\text { error of mean) }\end{array}$ & $\begin{array}{l}\text { Total protein (Mean } \pm \text { Standard } \\
\text { error of mean) }\end{array}$ \\
\hline Control & 0.625 & $31.55 \pm 1.45$ & $0.55 \pm 0.045$ & $3.05 \pm 0.15$ & $7.65 \pm 0.35$ \\
\hline $\mathrm{L}$ & 0.625 & $42.70 \pm 2.70$ & $0.31 \pm 0.01$ & $2.80 \pm 0.10$ & $7.95 \pm 0.35$ \\
\hline C3 & 0.625 & $32.70 \pm 0.10$ & $0.085 \pm 0.005$ & $3.00 \pm 0.10$ & $8.05 \pm 0.05$ \\
\hline Mix. & 0.625 & $33.95 \pm 1.25$ & $0.065 \pm 0.005$ & $2.95 \pm 0.05$ & $8.40 \pm 0.50$ \\
\hline
\end{tabular}

Alb: Albumin, TSP: Total serum protein

Table 18: Cytotoxicity Assays (AMJM) Cell of the Ligand and its Metal Complexes

\begin{tabular}{llllc}
\hline Comp. & Conc. $(\mathbf{6 . 1 2 5} \mu \mathbf{g} / \mathbf{m L})$ & Conc. $(\mathbf{1 2 . 5} \boldsymbol{\mu g} / \mathbf{L})$ & Conc. $(\mathbf{2 5} \mu \mathbf{g} / \mathbf{m L})$ & Conc. \\
\hline Cytotoxicity\% & & & & \\
Amoxicillin & 2.78 & 4.16 & 4.16 & 4.16 \\
L & 6.67 & 8.33 & 13.33 & 18.33 \\
C3 & 16.18 & 20.59 & 32.35 & 44.12 \\
Mix. & 16.07 & 32.04 & 48.08 & 49.78 \\
\hline
\end{tabular}

Table 19: Cytotoxicity Assays (SKOV-3) Cell of the Ligand and its Metal Complexes

\begin{tabular}{|c|c|c|c|c|c|}
\hline Comp. & Conc. $(6.125 \mu \mathrm{g} / \mathrm{L})$ & Conc. $(12.5 \mu \mathrm{g} / \mathrm{L})$ & Conc. $(25 \mu \mathrm{g} / \mathrm{mL})$ & Conc. $(50 \mu \mathrm{g} / \mathrm{mL})$ & Conc. $(100 \mu \mathrm{g} / \mathrm{mL})$ \\
\hline \multicolumn{6}{|l|}{ Cytotoxicity\% } \\
\hline Amoxicillin & 2.70 & 2.08 & 4.16 & 2.71 & 5.55 \\
\hline $\mathrm{L}$ & 6.67 & 8.33 & 13.33 & 18.33 & 23.33 \\
\hline $\mathrm{C} 3$ & 7.69 & 17.30 & 29.34 & 32.69 & 42.30 \\
\hline Mix. & 7.81 & 9.33 & 15.92 & 26.56 & 32.81 \\
\hline
\end{tabular}

Table 20: Cytotoxicity assays (MCF-7) cell of the ligand and its metal complexes

\begin{tabular}{llllc}
\hline Comp. & Conc. $(\mathbf{6 . 1 2 5} \mu \mathbf{g} / \mathbf{L})$ & Conc. $(\mathbf{1 2 . 5} \mu \mathbf{g} / \mathbf{L})$ & Conc. $(\mathbf{2 5} \mu \mathbf{g} / \mathbf{m L})$ & Conc. (50 $\mu \mathbf{g} / \mathbf{m L})$ \\
\hline Cytotoxicity\% & & & & Conc. (100 $\mu \mathbf{g} / \mathbf{L})$ \\
Amoxicillin & 3.12 & 2.34 & 4.68 & 3.12 \\
L & 2.63 & 3.94 & 6.57 & 6.57 \\
C3 & 16.70 & 21.71 & 25.05 & 21.70 \\
Mix. & 20.00 & 34.15 & 42.25 & 5.54 \\
\hline
\end{tabular}


Table 21: DPPH RSA for the ligand and its metal complexes with comparison ascorbic acid

\begin{tabular}{llll}
\hline Comp. & Conc. $(\mathbf{2 5} \boldsymbol{\mu g} / \mathbf{m L})$ & Conc. $(\mathbf{5 0} \boldsymbol{\mu g} / \mathbf{m L})$ & Ascorbic acid \\
\hline \multicolumn{2}{l}{ \% Scavinging activity } & & \\
L & 30 & 46 & 78 \\
C1 & 30 & 56.25 & 85 \\
C2 & 33.33 & 40 & 73.33 \\
C3 & 40 & 71.11 & 91.10 \\
Mix. & 37.78 & 62.22 & 77.78 \\
\hline
\end{tabular}

RSA: Radical scavenging activity

complexes, the results showed that the scavenging activity \% of C3 and Mix. ( $\mathrm{Cu}$ (II) complexes) were more than the free ligand and this is due to presence of $\mathrm{Cu}$ (II) ion [36], while the other complexes exhibited different scavenging activity. (Table 21)

\section{CONCLUSION}

New compound was synthesized by the insertion of boron on amoxicillin, also some metal complexes of this ligand were synthesized as well as we are synthesized the mixed ligand (copper complex with ligand and 4-aminoantipyrine) was synthesized. All compounds were characterized by different techniques. The antibacterial activities for all compounds were evaluation. The results showed that copper complexes were more active in $\left(10^{-2} \mathrm{M}\right)$ than the other compounds. The ligand (L) exhibited small activity with $S$. aureus compartion with its complexes, All synthesized compounds in $10^{-3} \mathrm{M}$ were more active from the amoxicillin against $S$. aureus. The medicinal studies were performed on the ligand and its metal complexes such as study the effect of synthesized compounds on the liver and kidney enzymes. The positive result were observed and the studied compounds improvement the activity of enzymes. Also the studies showed the positive results on the normal liver and kidney tissues. Another studies (anticancer and antioxidant activity) were carried out and the results were encouraging to use as anticancer and antioxidant agents.

\section{AUTHORS' CONTRIBUTION}

All authors have contributed equally.

\section{CONFLICTS OF INTEREST}

Authors have no conflicts of interest.

\section{REFERENCES}

1. Kistler RB, Helvaci. C. Boron and borates. Ind Miner Rocks 1994;6:171-86.

2. Dieter MP. Toxicity and carcinogenicity studies of boric acid in male and female B6C3F1 mice. Environ Health Perspect 1994;102 Supp1 7:93-7.

3. Karimi-Maleh H, Tahernejad-Javazmi F, Gupta VK, Ahmar H, Asadi MH. Anovel biosensor for liquid phase determination of glutathione and amoxicillin in biological and pharmaceutical samples using a $\mathrm{ZnO} / \mathrm{CNTs}$ nanocomposite/ catechol derivative modified electrode. J Mol Liq 2014;196:258-63.

4. Refat MS, Al-Maydama HM, Al-Azab FM, Amin RR, Jamil YM. Synthesis, thermal and spectroscopic behaviors of metal-drug complexes: $\mathrm{La}(\mathrm{III}), \mathrm{Ce}(\mathrm{III}), \mathrm{Sm}(\mathrm{III})$ and $\mathrm{Y}(\mathrm{III})$ amoxicillin trihydrate antibiotic drug complexes. Spectrochim Acta A Mol Biomol Spectrosc 2014; 128:427-46.

5. Li Y, Liu Y, Wang H, Xiong X, Wei P, Li F, et al. Synthesis, crystal structure, vibration spectral, and DFT studies of 4-aminoantipyrine and its derivatives. Molecules 2013;18:877-93.

6. Reitman S, Frankel S. A colorimetric method for the determination of serum glutamic oxalacetic and glutamic pyruvic transaminases. Am J Clin Pathol 1957;28:56-63.

7. Gometi SA, OguguaVN, Odo CE, Joshua PE. Effects of some antidiabetic plants on the hepatic marker enzymes of diabetic rats. Afr J Biotechnol 2014;13:905-9.

8. Kuan JC, Lau KY, Guilbault GG. Enzymatic determination of serum urea on the surface of silicone-rubber pads. Clin Chem 1975;21:67-70.

9. Artiss JD, McEnroe RJ, Zak B. Bilirubin interference in a peroxidase- coupled procedure for creatinine eliminated by bilirubin oxidase. Clin Chem 1984;30:1389-92.

10. Wayner DD, Burton GW, Ingold KU, Locke S. Quantitative measurement of the total, peroxyl radical-trapping antioxidant capability of human blood plasma by controlled peroxidation. The important contribution made by plasma proteins. FEBS Lett 1985;187:33-7.

11. Pérez-Serrano J, Denegri G, Casado N, Rodríguez-Caabeiro F. In vivo effect of oral albendazole and albendazole sulphoxide on development of secondary echinococcosis in mice. Int J Parasitol 1997;27:1341-5.

12. Fu W, Chen J, Cai Y, Lei Y, Chen L, Pei L, et al. Antioxidant, free radical scavenging, anti-inflammatory and hepatoprotective potential of the extract from Parathelypteris nipponica (Franch. Et sav.) ching. J Ethnopharmacol 2010;130:521-8.

13. Al-Shammari AM, Salman MI, Saihood YD, Yaseen NY, Raed K, Shaker HK, et al. In vitro synergistic enhancement of newcastle disease virus to 5-fluorouracil cytotoxicity against tumor cells. Biomedicines 2016;4:E3.

14. Sulaiman GM, Jabir MS, Hameed AH. Nanoscale modification of chrysin for improved of therapeutic efficiency and cytotoxicity. Artif Cells Nanomed Biotechnol 2018;46:708-20.

15. Al-Noor TH, Jarad AJ, Hussein AO. Synthetic, spectroscopic and antibacterial studies of $\mathrm{Fe}$ (II), $\mathrm{Co}$ (II), Ni (II), Cu (II), $\mathrm{Zn}$ (II), Cd (II) and $\mathrm{Hg}$ (II), mixed ligand complexes of saccharin and amoxicillin (antibiotics). Chem Mater Res 2014;6:20-30.

16. Piskin S, Yilmaz MS. Production of Methyl Borate for Sodium Borohydride (NaBH4): Hydrogen Storage Medium. Bangkok: In: International Conference on Chemistry and Chemical Process; 2011.

17. Ansari RM, Bhat BR. Schiff base transition metal complexes for suzuki miyaura cross-coupling reaction. J Chem Sci 2017;129:1483-90.

18. Mohammed AM, Salim JS. Synthesis and biological evaluation of new boron compound with cephalexin and some of its transition metal complexes. J Glob Pharm Technol 2018;10:640-9.

19. Spinu C, Kriza A. Co (II), Ni (II) and Cu (II) complexes of bidentate Schiff bases. Acta Chim Slov 2000;47:179-86.

20. Tomi IH, Abdullah AH, Al-Daraji AH, Abbass SA. Synthesis, characterization and comparative study the antibacterial activities of some imine-amoxicillin derivatives. Eur J Chem 2013;4:153-6.

21. Martin C, Ronda J, Cadiz V. Boron-containing novolac resins as flame retardant materials. Polym Degrad Stab 2006;91:747-54.

22. Mohammed A. Synthesis and biological evaluation of new boron compound with cephalexin and some of its transition metal complexes. J Glob Pharm Technol 2018;10:640-9.

23. Fleming I, Williams DH. Spectroscopic Methods in Organic Chemistry. London: McGraw-Hill; 1966.

24. Al-Abidy N. Synthesis, Characterization and Study of the Biological Activity of New Mannich-Schiff Bases and Some Metal Complexes Derived from Isatin, 3-Amino-1, 2, 4-Triazol and Dithiooxamide. Iraq: University of Baghdad Baghdad; 2006.

25. Al-Jeboori FH, Al-Shimiesawi TA, Oun MA, Abd-ul-Ridha A, Abdulla AY. Synthesis and characterization of amino acid (phenylalanine) schiff bases and their metal complexes. J Chem Pharma Res 2014;6:44-53.

26. Figgis BN. Introduction to Ligand Fields. New York: Interscience Publishers; 1966.

27. Geary WJ. The use of conductivity measurements in organic solvents for the characterisation of coordination compounds. Coord Chem Rev 1971;7:81-122.

28. Badea M, Olar R, Uivarosi V, Marinescu D, Aldea V, Barbuceanu SF, et al. Thermal behavior of some vanadyl complexes with flavone derivatives as potential insulin-mimetic agents. J Therm Anal Calorim 2011;105:559-64.

29. Scorei RI, Popa R Jr. Boron-containing compounds as preventive and chemotherapeutic agents for cancer. Anticancer Agents Med Chem 2010;10:346-51.

30. Rajput R, Mishra AP. A review on biological activity of quinazolinones. Int J Pharm Sci 2012;4:66-70.

31. Banik I, Becker FF, Banik BK. Stereoselective synthesis of betalactams with polyaromatic imines: Entry to new and novel anticancer agents. J Med Chem 2003;46:12-5.

32. Creaven BS, Duff B, Egan DA, Kavanagh K, Rosair G, Thangella VR, et al. Anticancer and antifungal activity of Copper (II) complexes of quinolin-2 $(1 \mathrm{H})$-one-derived Schiff bases. Inorganica Chim Acta 2010;363:4048-58.

33. Verlee A, Mincke S, Stevens CV. Recent developments in antibacterial and antifungal chitosan and its derivatives. Carbohydr Polym 2017;164:268-83.

34. Prakash CR, Raja S, Saravanan G. Synthesis, characterization and anticonvulsant activity of novel Schiff base of isatin derivatives. Int J 
Pharm Sci 2010;2:177-81.

35. Amarowicz R, Pegg R, Rahimi-Moghaddam P, Barl B, Weil J. Freeradical scavenging capacity and antioxidant activity of selected plant species from the Canadian prairies. Food Chem 2004;84:551-62.
36. Barik A, Mishra B, Shen L, Mohan H, Kadam RM, Dutta S, et al. Evaluation of a new Copper(II)-curcumin complex as superoxide dismutase mimic and its free radical reactions. Free Radic Biol Med 2005;39:811-22. 